
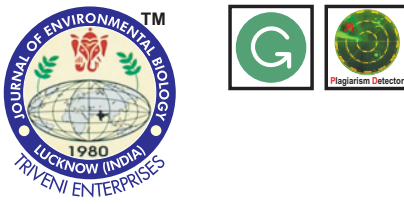

\title{
Mountain regions, population and their ecological problems: Case study of Mestia municipality
}

\section{Authors Info}

T. Khardziani, M. Elizbarashvili*, R. Maisuradze, K. Bilashvili, Z. Seperteladze, T. Khuntselia, T. Eradze, E. Davitaia, N. Jamaspashvili, G. Dvalashvili, T. Aleksidze, M. Sharashenidze, N. Rukhadze and T. Gordeziani

Department of Geography, Faculty of Exact and Natural Sciences, Ivane Javakhishvili Tbilisi State University, Tbilisi, 0179, Georgia

*Corresponding Author Email : mariam.elizbarashvili@tsu.ge

Key words Ecological problems, Mountain regions, Population attitude

Publication Info Paper received : 18.08 .2016 Revised received : 23.06.2017 Accepted : 28.06.2017

\section{Abstract}

Aim: Mountain regions face specific challenges which require appropriate policies implemented in accordance with the principle of sustainable development. The most important aspect of sustainable development is direct consideration of population needs when drawing the development plan. Thus, the aim of the study was to analyze the opinions, attitudes and behavior of Mestia municipality population towards the environment and identify the most important ecological problems.

Methodology: 895 people were surveyed in Mestia municipality. Stratified and cluster selection methods were used for selection of respondents and compilation of database. SPSS package was used for statistical analysis of survey results.

Results: During the study, $30.9 \%$ of population under taken during the survey of Mestia municipality advocated landslide-mud flow processes as one of the major ecological problems. Seventeen percent of respondents revealed that unavailability/failure of sewerage systems is the number one ecological problem, whereas $13.9 \%$ climate changes, extreme weather and climatic events and floods.

Interpretation: Obtained results are essential for elaboration of strategies for sustainable development of various regions and are also quite interesting that indicates or reveals an example of environment and mountain regions' population interdependence.

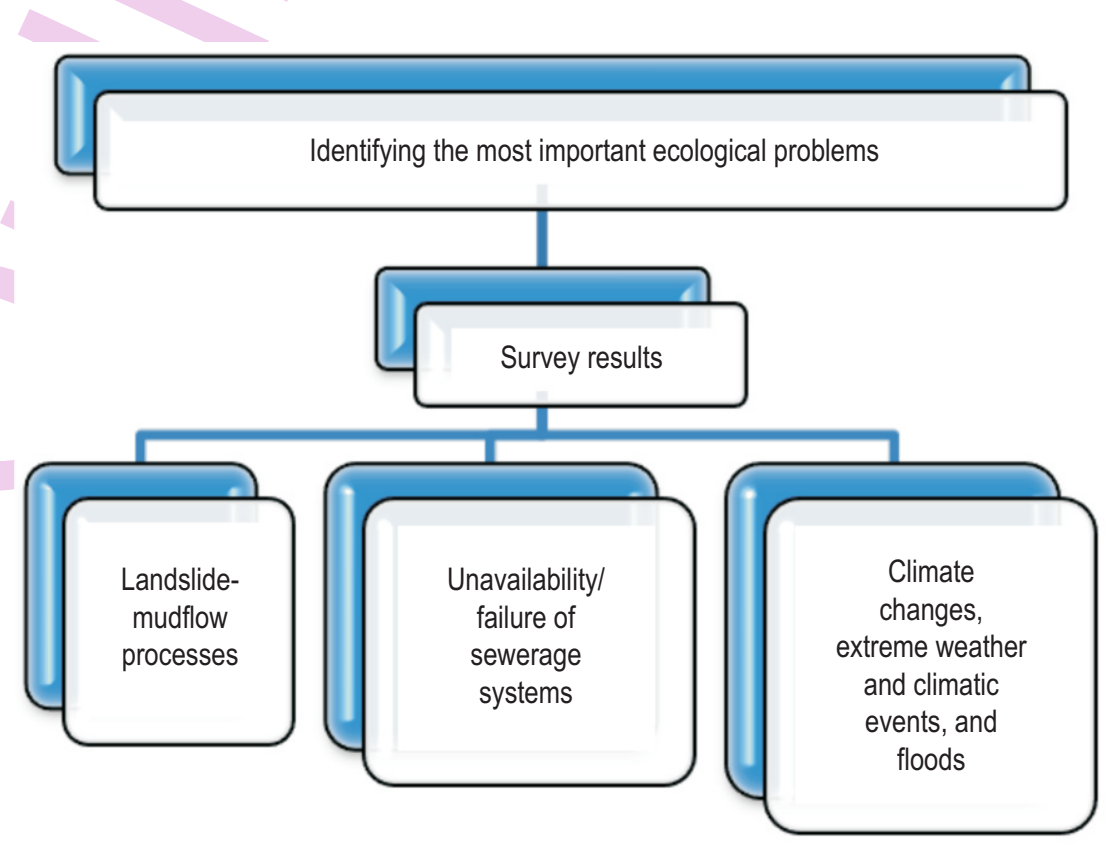




\section{Introduction}

Mountains play a key role in the impact on regional and global climate, on the other hand high-mountain territories are especially sensitive to climate changes. Snow avalanches, landslides, rock avalanches, stone falls, storm flows and erosive and/or destructive action of rivers are among the major problems for mountain population. Mentioned phenomena frequently threaten not only residential structures, but also agricultural lands, roads, communications and other infra structural facilities etc. Mountain ecosystems are important for long-term global development, overcoming poverty and for transition to green economy. Thus, sustainable development of mountain regions is a global priority. Georgia as a mountainous country strives for sustainable development of regions that is reflected in appropriate laws. Sustainable development equally implies the improvement of environment, economic, social and cultural environment of local society. Therefore, an important aspect of sustainable development is an understanding of domestic needs and their direct consideration when projecting a development plan (Guang et al., 2016; Lorenzoni and Pidgeon, 2006; Kingston et al., 2000; Smith, 2010, Smith, 2011). In this context, survey was carried out to establish the opinions, attitudes and behavior of mountain region population towards the environment and identify the most important ecological problems in the context of regional development.

Georgia is a classic example of the country, where mountain regions cover significant territory of the state. Mestia municipality is located in Samegrelo-Zemo Svaneti region of Western Georgia, total area of which is 304.450 ha were agricultural land occupies 94,000 ha that is approximately $31 \%$ of the total territory. In its turn, forests occupy roughly $46 \%$ of territory. Mestia municipality is the most high-mountain region of Georgia. Its hypsometric altitude varies from $450 \mathrm{~m}$ (Jvari water reservoir) to $5.202 \mathrm{~m}$ (Shkhara mountain). Mestia municipality is one of the largest Georgian municipalities, whose population is relatively small in context to its area. Population density is approximately 5 people $\mathrm{km}^{-2}$ that is 13 times lesser than average index countrywide (67 people $\mathrm{km}^{-2}$ ). Due to this fact, population's attitude to ecological problems is of great importance, since the issue of population preservation in mountain and high-mountain regions are frequently depended on the mentioned problems.

Currently, in Mestia municipality the process of rapid development of tourism industry and the region naturally faces new challenges.

\section{Materials and Methods}

The study is based on the results of population survey which was carried out in Mestia municipality. The questionnaire was elaborated taking into account the peculiarities of Mestia municipality. Electoral database of the last Parliamentary election
(2012) and stratified and cluster selection methods were used for selection of respondents and compilation of database.

Stratified selection implies population division into stratums according to one of another characteristic (age, gender, dwelling, social class) and creation of respondents' group by random selection from each stratum with the purpose of improvement of selection's representativeness. Cluster selection selected groups under study from kindred unity (group) - clusters and less addresses to random selection. In the present study, the case stratification variable is represented by Mestia municipality communities, while cluster was introduced by district.

During stratified and cluster selection the error was calculated by the following formula:

$$
\Delta_{\text {strat+clasr }} \leq \frac{1}{\sqrt{n}} \times 100 \%
$$

where, $\mathrm{n}$ is the number of interrogated respondents.

Sampling error implies $95 \%$ range of validity. Number and error of interrogated respondents was determined both for municipality as a whole and for each community. For Mestia municipality, the number of respondents were 895 and error was 3.3.

For statistical analysis of polling, data was used the SPSS package, which currently is widely used for statistical analysis worldwide (Landaua and Everitt, (2004)).

895 respondents were surveyed with the following questionnaire: Name three most important ecological problems from the list and give number 1-3 according to their priorities.

Q1 : Landslides and Mudflows;

Q2 : Avalanches;

Q.3 : Climate change, extreme weather and climate events, floods;

Q4 : Logging;

Q5 : Growing number of domestic, construction and other waste;

Q6 : Reduction of biodiversity;

Q7 : Expansion of imported breeds and species and their negative impact on local breeds and environment;

Q6 : Distribution of plant pests and diseases;

Q9 : Animal diseases and their vulnerability; 


\section{Q.10: Contamination of drinking water;}

Q11：Unavailability/failure of sewerage systems;

Q12 : Environmental impact on the cultural heritage;

Q13 : The loss of environmental traditions.

\section{Results and Discussion}

On the basis of statistical analysis of survey results for the municipality as a whole were identified enduring ecological problems, which are most important in population opinion.

$30.9 \%$ of interrogated population of Mestia municipality considered landslide-mudflow processes as the number one ecological problem, $17 \%$ of respondents supposed that unavailability/failure of sewerage systems is the number one ecological problem, $13.9 \%$ of surveyed persons - climate changes, extreme weather and climatic events and floods, $9.5 \%$ of respondents - growing number of domestic, construction and other waste as the major challenge; $6.2 \%$ of respondents avalanches, $6.0 \%$ - pollution of drinking water, $5.6 \%$ - irrational forest felling, $3.9 \%$ - distribution of plant pests and diseases, $2.1 \%$ - animal diseases and their vulnerability; $2.1 \%$ - expansion of imported breeds and species and their negative impact on local breeds and environment; $0.7 \%$ - reduction of biodiversity (animal and plant species). As we can see landslide-mudflow processes were regarded as the number one ecological problem.

In population's opinion, landslide-mudflow processes, unavailability/failure of sewerage system and climate changes, extreme weather and climate events, floods were among the most important ecological problems of Mestia municipality. Population's opinion is in good agreement with the reality, since floods, landslides, mudflows, avalanches, stream-bank erosion is characteristic for Mestia municipality. Among them landslides were most frequent, followed by floods and mud flows. During the last many years several villages had suffered due to landslides. The same events often occured in different places of Daba Mestia. More than 400 families suffered in last years due to landslides, avalanches, mud flows and floods in Mestia municipality. Landslides had harmed 180 houses, avalanches 2 houses, while floods and freshets -20 houses. 32 families lived in hazardous zone. 466 families of Mulakhi community were awarded by category. 28 families were moved to Kakheti region; 94 families took money as compensation, part of families were relocated to Tsalka, TetriTskaro and Gardabani.

Landslide-mudflow processes caused threat not only to residential houses of Mestia municipality, but also to cropland areas and public infrastructure. Floods and landslides, almost in each village, caused damage to inter-village roads and bridges, leading to stream-bank erosion and damaging the cropland areas located near river flood basins. In last few years, four central bridges and nearly 35 rural bridges were destroyed due to floods. In some communities, the landslide had demolished water-supply system and electricity transmission line. Avalanche had harmed Daba Mestia roads, and stone fall had destroyed the central roads.

Thus, it can be conclude that Mestia municipality population objectively realizes and recognizes the ecological problems facing several years. In population opinion, landslidemudflow processes represent the most important problem for Mestia municipality. Also, major part of population considers failure of sewerage system as vitally important problem. In fact, except for DabaMestia, today there are no sewerage systems in any community. This problem becomes especially acute against the background of growing tourism in the municipality.

Year-long tradition of coexistence of nature and society is established in Mestia municipality that is reflected in unique peculiarities of land utilization (under conditions of land scarcity), forest utilization and other local economies that makes this region unique. Plenty of building and structures, monuments of architecture and high cultural value, which are typical for mountain regions is an illustrative example of the fact that region is outstanding and very interesting.

Besides, rapid development of region from touristic view point, expansion of appropriate infrastructure takes place here, and more and more people from different countries express a wish to visit this region. Development of tourism industry as a nontraditional sector of economy faces new challenges. In contradistinction from land utilization and forest exploitation, no historical experience is know in this sphere among the population, and this fact may become a precondition of some negative effect. On that basis it is necessary to work out the strategy of sustainable regional development that must provide such level of development for a new sector of economy that will allow to keep the balance, which is traditionally established between population and environment. We suppose that results of the present study are important for elaboration of strategy of sustainable development of the region and scheduling of preventive measures.

\section{References}

Guang, Y., S. Ge and L. Han: The development of ecological environment in China based on the system dynamics method from the society, economy and environment perspective. J. Environ. Biol., 37, 155$162(2016)$.

Lorenzoni, I. and N. F. Pidgeon: Public views on climate change: European and USA Perspectives, Climatic Change, 77, 73-95 (2006).

Kingston, R., S. Carver, A. Evans and I. Turton: Web-based public participation geographical information systems: An aid to local environmental decision-making. Comp. Environ. Urb. Syst., 24, 109-125(2000). 
Landau, S. and B.S. Everitt: Handbook of Statistical Analyses using SPSS. (2004).

Smith, T.W.: Public attitudes towards climate change and other environmental issues across time and countries, 1993-2010; NORC at the University of Chicago (2010).
Strategic Options towards Sustainable Development in Mountainous Regions, A Case Study on ZemoSvaneti, Georgia, Centre of Advanced Training in Rural Development (2006).

The Environment: Public Attitudes and Individual Behavior -A TwentyYear Evolution (2011). 